\title{
The Biochemical Relevance of Different Types of Oxidative Stress at the Ocular Level
}

\author{
RAZVAN UNTU ${ }^{1}$, CARMEN LACRAMIOARA ZAMFIR ${ }^{1 *}$, MIHAELA BOANCA ${ }^{1 *}$, RALUCA OANA TEMNEANU, FLORIN ELOAIE ZUGUN ${ }^{1}$, \\ CRISTINA GALES ${ }^{1}$, ALEXANDRA-SIMONA ZAMFIR ${ }^{1}$, LILIANA STRAT ${ }^{1}$, ROXANA FOLESCU ${ }^{2}$, MIHAELA SPATARU ${ }^{3}$ \\ ${ }^{1}$ Grigore T. Popa University of Medicine and Pharmacy, 16 Universitatii Str., 700115, lasi, Romania \\ 'Victor Babe' University of Medicine and Pharmacy Timisoara, 2 Eftimie Murgu Sq, 300041, Timisoara, Romania \\ ${ }_{3}^{3}$ Ion Ionescu de la Brad University of Agricultural Sciences and Veterinary Medicine,3 Mihail Sadoveanu Str,700489, Iasi, Romania
}

\begin{abstract}
The connection between oxidative stress and ocular injuries was highly debated, given the fact that, as a result of its particular structure, the eye may have different reactions when exposed to oxidative stress and visual activity and functionality are considerable compromised. Our experimental research focused on two types of induced oxidative stress on rats (disruption of circadian rhythm and diabetes mellitus) with impact on biochemical markers of oxidative stress. We have analysed the amplitude of significant antioxidant markers correlated with each individual type of antioxidant disorder. We observed alterations of stress biomarkers for all induced types of stress, but the most relevant are associated with diabetes mellitus and light exposure.
\end{abstract}

Keywords: oxidative stress, eye, circadian rhythm, diabetes mellitus

Oxidative stress, classically defined as an imbalance between an overproduction of reactive oxygen species and the antioxidant capacity of the organism, has a significant impact on visual activities and functions [1]. A welldeveloped antioxidant system has the capacity to neutralise or to reduce the oxidative mechanisms, until this endogenous defence is no more able to counter balance it. There is current evidence to support the fact that the eye, as a result of its particular structural complexity, is a very sensitive organ to oxidative aggression. The simultaneous presence in the eye of distinct transparent and opaque components will determine a diverse range of ophthalmic reactions when oxidative stress is exerted at local level [2]. The relationship between oxidative stress and ophthalmic pathology has to considerate the particular involvement of different types of oxidative stress [3].

The light-dark cycle, as a part of chronobiologic clock, is very important for setting and regulating visual activities [4]. The daily environmental light-dark sequence not only display a specific ocular circadian rhythmicity, but also generates an integrative control to maintain normal vision. In the context of the entire organism, we can mention that the eye individual circadian clock is active in coordinating diverse cellular responses to environmental factors $[5,6]$.

Diabetes mellitus, as metabolic disease, extends its negative consequences to the eye, with a complex alteration of ocular microvasculature, generating a large area of ocular pathology. Oxidative stress is recognized to play a distinct role in diabetes pathogenesis through its reactive oxygen species. The oxidative alterations may determine irreversible ocular damage, affecting homeostasis and mitochondrial production of reactive species; within this context, diabetes impairs antioxidant defence and facilitates development of different types of alterations $[7,8]$.

A significant number of studies are focused on determining if the oxidative stress initiates and accelerates ophthalmic alterations or it is a well determined result of these alterations. The exposure of the organism to environmental factors generating oxidative stress is intimately correlated with extensive ocular damage. The different mechanisms through which oxidative stress is getting involved in visual damage have a different impact on visual components. There is a growing body of evidence that suggests the fact that oxidative stress is related to ophthalmic pathology, thereby remains still difficult to be able to distinguish between different types of oxidative stress and their influence on different visual components [9-11].

\section{Experimental part \\ Materials and methods}

28 male Wistar rats with a weight of 250-290 g were used for this experiment; they were provided with standard diet and water ad libitum. The animals were acclimatized a week before starting the study and maintained under controlled conditions of temperature, humidity, with a 12 hours light/dark cycle. The rats were randomly distributed in 4 distinct groups: control group, a group maintained at continuous light, a group maintained at continuous dark, and a group with induced diabetes mellitus. In order to induce diabetes in experimental animals, we have used streptozotocin in an unique intraperitoneally administration, $65 \mathrm{mg} / \mathrm{kg}$ body weight, as shown in the literature [12]. The blood glucose level was measured with glucometer from two in two days, diabetes being confirmed and maintained through the whole experiment. The weight of the rats was determined at the beginning and at the end of the experiment. After four weeks, at the end of the experiment, after blood was collected for antioxidants biochemical exam, the animals were euthanatized and the eyes together with the optic nerve were removed for histopathologic exam.

\section{Biochemical assay}

SOD was determined using Sun method [13]. CAT was determined based on Aebi method [14]. Total antioxidant status (TAS) was evaluated by the colorimetric method.

\footnotetext{
*email:zamfircia@yahoo.com; boanca.mihaela@umfiasi.ro
} 


\section{Results and discussions}

We determined the weight of all the animals in order to monitor the general status of their organism, during the process of oxidative stress initiation and development. Compared with control group, all analysed groups presented a decrease of their initial weight, more accentuated in the groups with diabetes and lightexposure (fig.1).

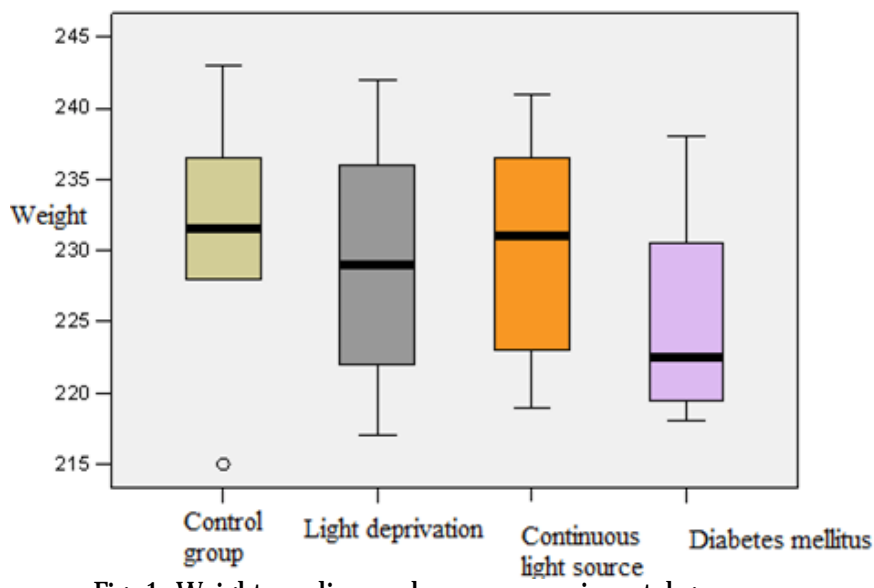

Fig. 1. Weight medium values on experimental groups

SOD activity was significantly decreased in all experimental groups, with a pronounced fall in case of induced diabetes mellitus and light exposure; the group maintained in continuous dark exposure presented a decrease of SOD values, but smaller than the other two experimental groups (fig. 2).

The correlation SOD/weight for all four groups of rats suggests that bigger values of the weight are associated with bigger values of SOD, but the results are not always statistically significant (fig. 3).

TAS evolution marked a decrease for both light exposure and diabetes mellitus group (fig. 4).

The correlation TAS/weight was direct and moderate for diabetes group, while in continuous light exposure group

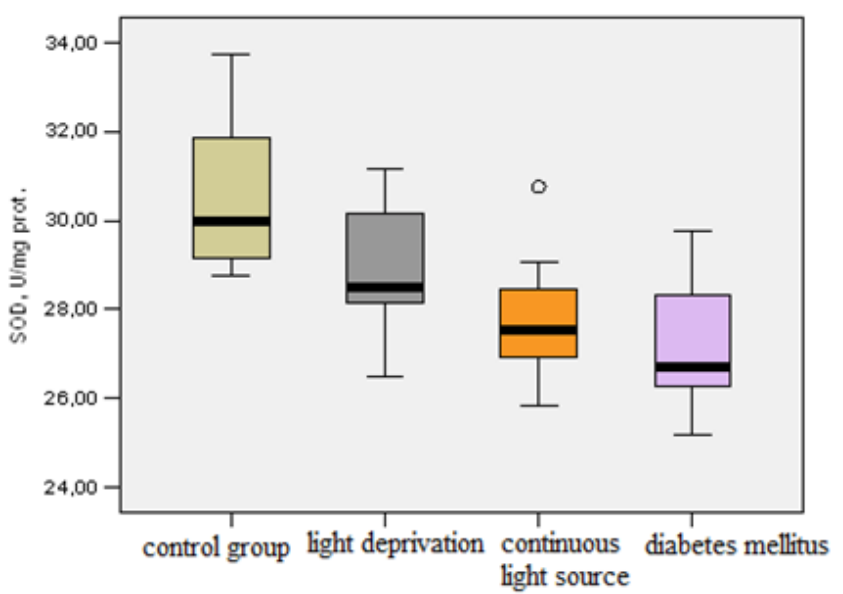

Fig.2. SOD medium values reported to experimental groups.

this correlation was following the same direction as SOD (fig. 5).

Reactive Oxygen Species (ROS) over expression is now recognized to play a complex function related to multiple mechanisms which generate a diverse background for eye pathology. The circadian rhythmicity ensures not only an optimal accommodation with environment conditions, but also a normal visual performance. When the organism cannot anticipate or accommodate to environmental changes, the oxidative stress determines massive disorders in organs and systems, including the eyes [15, 16]. The failure of reducing or maintaining under control the oxidative stress (too long, or too intense) determine an intracellular sequence of events, which compromise in a variable manner the visual structure and function. The disruption of normal light exposure may impact the eye, triggering profound alterations of ocular structures [17, 18].

Our study revealed the fact that a continuous light exposure affects the eye and it is reflected through a diminished level of antioxidant enzymes and TAS, more relevant than in case of dark exposure [19].

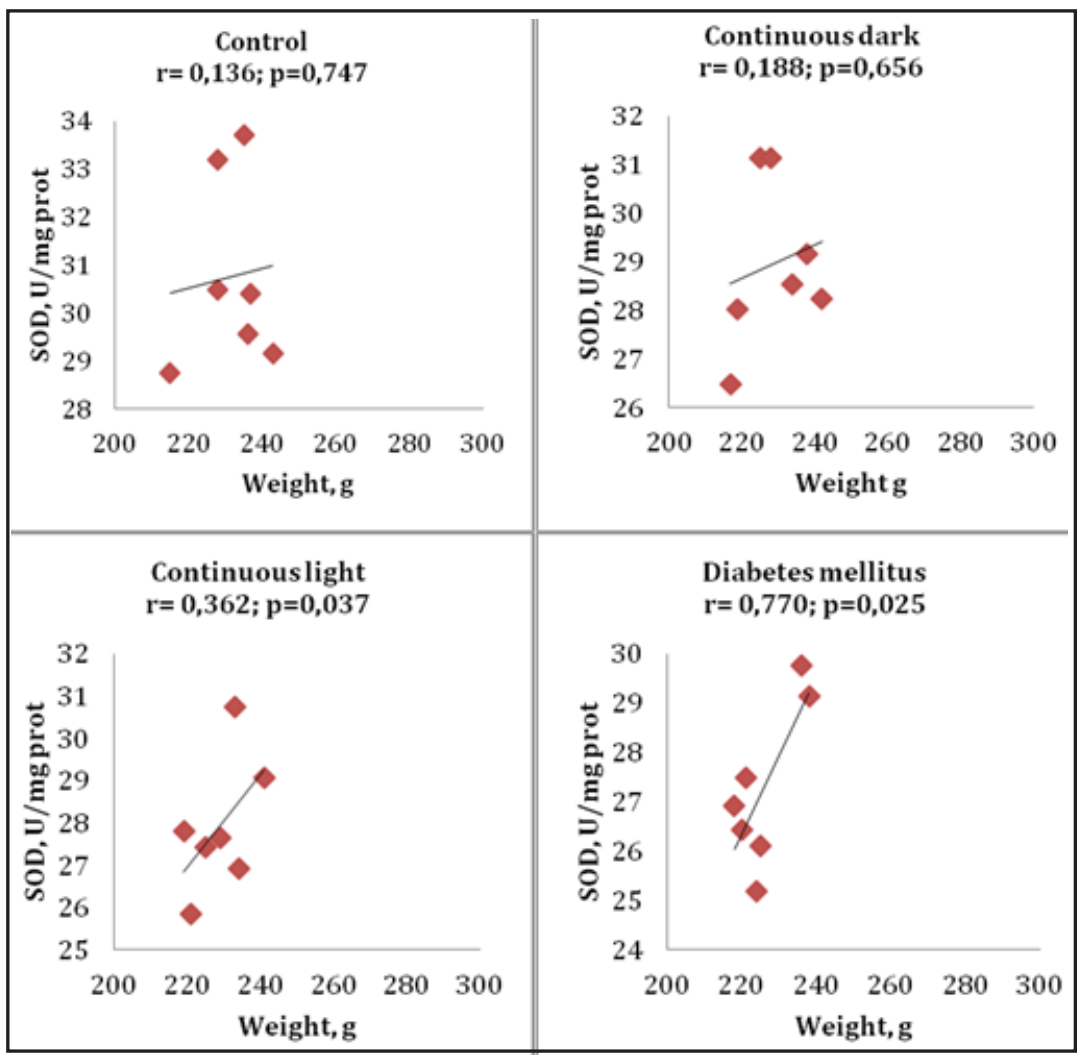

Fig. 3 SOD/weight correlation 


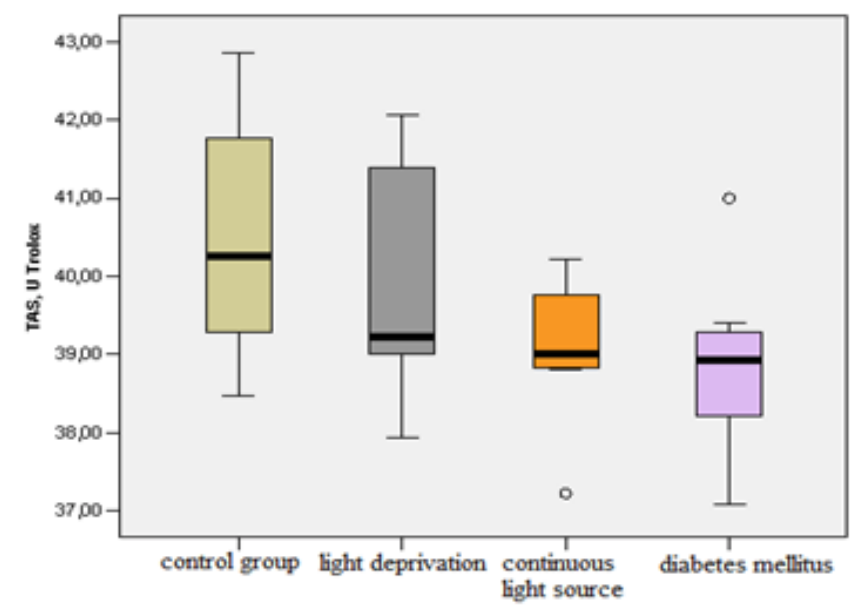

Fig.4. TAS medium values reported to experimental groups.

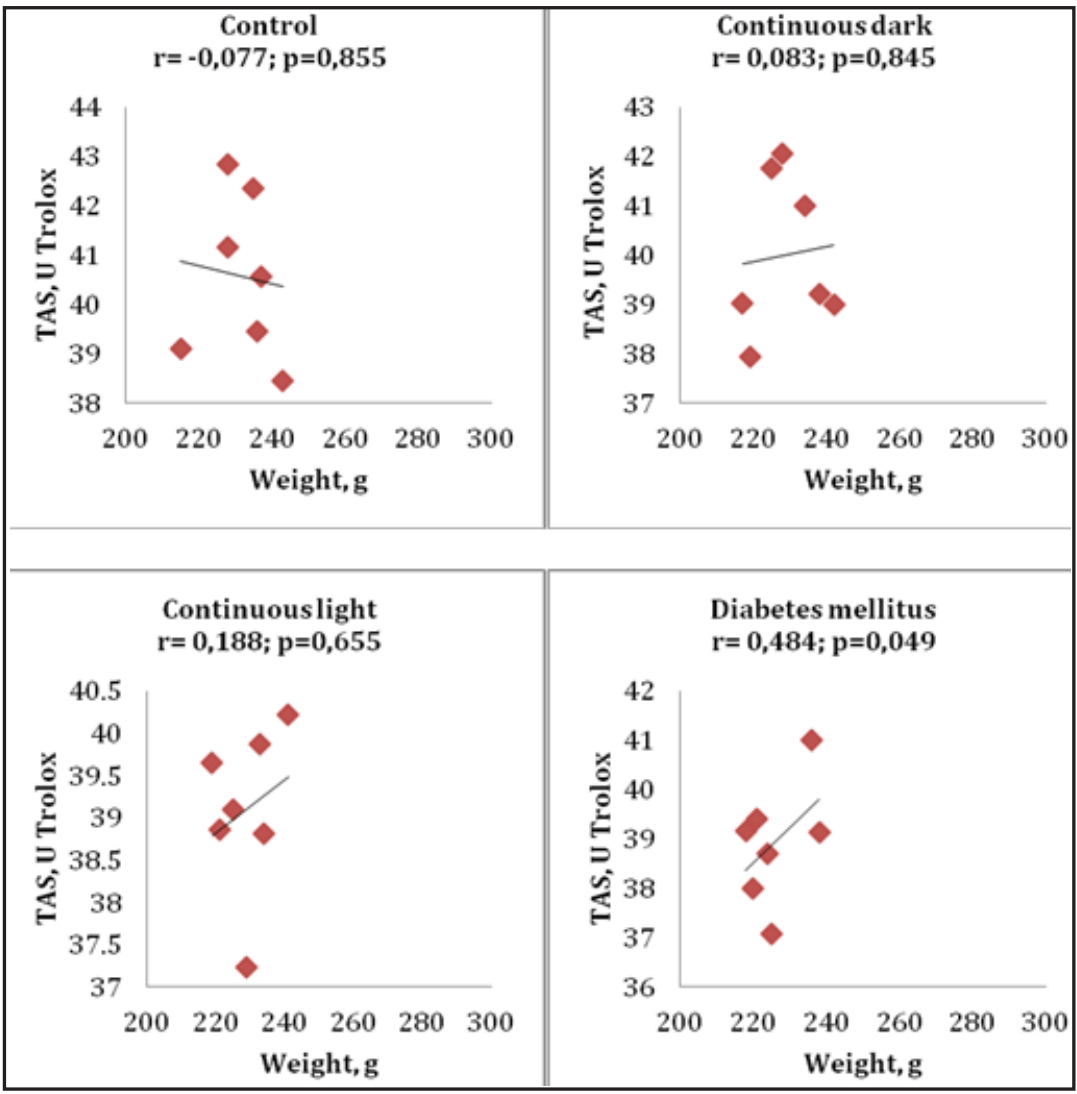

Fig. 5 TAS/weight correlation.

On the other hand, diabetes mellitus and oxidative stress are recognized to be intimately correlated, the role of ROS in diabetic pathogenesis is well determined and the ocular diabetic complications are frequently associated with oxidative stress-cataract, dry eye syndrome, glaucoma, retinal disorders, etc. There are mentioned some distinct pathways for sources of oxidative stress in diabetes, each of them with specific implications in diabetic pathology $[20,21]$. The ocular surface is very vulnerable to oxidative stress and its properties change as a result of stress. Microand macro vessels are affected by hyperglycaemia, endothelial cells become dysfunctional and play a critical role in severe changes along the vascular wall [22].

In our experiment, the biomarkers of the oxidative stress were significantly affected during diabetes mellitus and during circadian rhythm disorders (more obvious in light exposure). In the same context, it seems interesting to mention that we can notice the existence of a very special connection between circadian rhythms and diabetes mellitus, based on the fact that circadian dis-rhythmicity has a serious influence on ophthalmic diabetic complications $[23,24]$. From the control of insulin pancreatic production to rhythmic evolution of cellular processes in the eye, there is a profound synchronization between eye performance and internal/external body clock.

\section{Conclusions}

Research of oxidative stress on ocular level has to be correlated with the specific type of oxidative aggression. Oxidative stress generates visual impairment and is reflected in the biochemical assay of the specific biomarkers. SOD and TAS decrease with progressive exposure to induced oxidative stress, in a significant manner for diabetes mellitus and light exposure and in a less accentuated manner in dark exposure. We can suggest an intimate correlation between the type of oxidative stress and the answer of the antioxidant defence.

\section{References}

1.SIES, H., Experimental Physiology, 82, 1997, p. 291.

2.WILKING, M., NDIAYE, M., MUKHTAR, H., AHMAD, N., Antioxid. Redox Signal, 19, No. 2, 2013, p. 192.

3.KRUK, J., KUBASIK-KLADNA, K., ABOUL-ENEIN, H.Y., Mini-Reviews in Medicinal Chemistry, 16, No. 3, 2015, p.241. 
4.WIECHMANN, A.F., SUMMERS, J.A., Progress in Retinal and Eye Research, 27, No. 2, 2008, p. 137.

5.HARDELAND, R., COTO-MONTES, A., POEGGELER, B., Chronobiol. Int., 20, 2003, p.921.

6.BARTOSZ, G., Biochem. Pharmacol., 77, 2009, p.1303.

7.FERNANDES, S.M., CORDEIRO, P.M., WATANABE, M., FONSECA, C.D.D, VATTIMO, M.D.F.F., Arch. Endocrinol. Metab., 60, No. 5, 2016, p. 443.

8.BIRBEN, E., SAHINER, U.M., SACKESEN, C., ERZURUM, S., KALAYCI, O., World Allergy Organ., 5, 2012, p.9.

9.PAN, H., ZHANG, H., CHANG, D., British J ournal of Ophthalmology, 92, 2008, p. 548.

10.WILKING, M., NDIAYE, M, MUKHTAR, H., AHMAD, N., Antioxidants \& Redox Signaling, 19, 2013, p. 192.

11.ALEXA, A., CANTEMIR, A., ANTIOCH, I., BALMUS, I.M., COJOCARU, S., GARDIKIOTIS, R., LUCA, A., FILIP, M.A., ABABEI, D.C., ZAMFIR, C.L., Rev. Chim. (Bucharest), 68, no. 2, 2017, p. 350.

12.KUMAR, B., GUPTA, S.K., NAG, T.C., et al, Experimental Eye Research, 123, 2014, p. 193.

13.SUN, Y., OBERLEY, L.W., LI, Y., Clin.. Chem., 343, 1988, p.497. 14.WILLIAMS, D.L., Vet. Clin. North Am. Small Anim. Pract., 38, 2008, p. 179.

15.TEMNEANU, R.O., MOTOC, A.M., ZUGUN, F.E., FOLESCU, R., LUPUSORU, C.E., ZAMFIR, C.L., Rom. J. Morphol. Embryol., 53, No. 2, 2012 ,p. 789.
16.GOLOMBEK, D.A., ROSENSTEIN, RE., Physiol. Rev, 90, 2010, p. 1063.

17.COLIN-GONZALES, A.L., AGUILERA, G., SERRATOS, I.N., ESCRIBANO, B.M., SANTAMARIA, A., TUNEZ, I., Curr. Pharm. Des., 21, 2015, p. 3477.

18.REITER, R.J., ROSALES-CORRAL, S., COTO-MONTES, A., BOGA, J.A., TAN, D.X., DAVIS, J.M., KONTUREK, P.C., KONTUREK, S.J., BRZOZOWSKI, T., J. Physiol. Pharm., 62, 2011, p. 269.

19.BUETTNER, G.R., Anti-Cancer Agents in Medicinal Chemistry, 11, 2011, p.341.

20.J OHANSEN, J.S., HARRIS, A.K., RYCHLY, D.J ., ERGUL, A., Cardiovasc. Diabetol., 4, 2005, doi: 10.1186/1475-2840-4-5.

21.SHAW, A., DOHERTY, M.K., MUTCH, N.J., MACRURY, S.M., MEGSON, I.L., Biochem. Soc. Trans., 42, No.4, 2014, p. 928.

22.MILAS, O., GADALEAN, F., VLAD, A., DUMITRASCU, V., GIUHOVSCHI, C., GIUHOVSCHI, G., VELCIOV, S., POPESCU, R., BOB, F., MATUSZ, P., PUSZTAI, A.M., CRETU, O.M., SECARA, A., SIMULESCU, A., URSONIU, S., VLAD, D., PETRICA, L., J ournal of Investigative Medicine, 66, 2018, p. 747.

23.FELDER-SCHMITTBUHL, M.P., BUHR, E.D., DKHISSI-BENYAHYA, O., HICKS, D., PEIRSON, S.N., RYBELAIGA, C.P., SANDU, C., SPESSERT, R., TOSINI, G., Investigative Ophthalmology \& Visual Science, 59, No. 12, 2018, p. 4856, doi: 10.1167/iovs.18-24957.

24.BESHARSE, J.C., MCMAHON, D.G., J. Biol. Rhythms, 31, No 3, 2016, p. 223.

$\overline{\text { Manuscript received: } 22.12 .2018}$ 